\title{
Failure Behavior of Cemented Carbide under Impact-Sliding Wear Conditions
}

\author{
D.Q. Tan*, X.Q. Yang, Q. He and H.Y. Gao \\ Aviation Engineering College, Civil Aviation Flight University of China, Guanghan 618307, P. R. China
}

\begin{abstract}
A wear test set-up is designed and employed to investigate the damage behavior and failure mechanisms of cemented carbide against $\mathrm{Si}_{3} \mathrm{~N}_{4}$ ceramic under impact-sliding wear conditions to understand the damage trend of cutting tools under complex relative motions. The wear profile, damage morphology, and chemical components of the cemented carbide are analyzed for different number of test cycles. The results demonstrate that the damage type of the cemented carbide under impact-sliding wear conditions is primarily delamination of the impact area, whereas the damage of the sliding zone is negligible. The damage characteristics of impact-sliding wear of cemented carbide do not change significantly with an increase in the number of cycles, but the wear rate decreases. Oxidative wear is observed in the impact area, producing black wear debris consisting of $\mathrm{WO}_{3}$. The failure of the cemented carbide under impact-sliding wear conditions is primarily mainly caused by delamination induced by fatigue wear, as well as oxidative wear. [doi:10.2320/matertrans.MT-M2021014]
\end{abstract}

(Received January 26, 2021; Accepted June 7, 2021; Published August 25, 2021)

Keywords: cemented carbide, impact-sliding wear, complex wear, failure mechanisms, damage evolution, tribochemical behavior

\section{Introduction}

As one of the most widely used cutting tool materials, ${ }^{1)}$ cemented carbides have high hardness, good wear resistance, high strength and toughness, excellent chemical stability, good thermal performance, and satisfactory corrosion resistance. ${ }^{2)}$ Currently, cemented carbides account for more than $70 \%$ of the tool market. ${ }^{3)}$ Common turning tools, milling cutters, planers, drills, and boring tools mostly consist of cemented carbides. Wear resistance is one of the most important target characteristics of tool materials; thus, it is necessary to investigate the properties of tool materials. ${ }^{4-6)}$

Previous studies of tribological behaviors of cemented carbides focused on the tribological evaluation of a single motion form or traditional rotary cutting simulation, ${ }^{7,8)}$ including sliding wear tests, ${ }^{9-14)}$ impact wear tests, ${ }^{15)}$ ballon-disc wear tests, ${ }^{16)}$ and ring-block tests. ${ }^{17)}$

The use range, environment, and load conditions of cemented carbides are constantly changing due to continuous development. The relative movement between the friction surfaces of cemented carbides is very complex under actual working conditions, and multiple forms of wear occur. For example, the tunnel boring machine industry has developed rapidly due to the increasing construction of subways, highspeed railways, and highways, and developments in other fields. Cemented carbide tools bear an impact load and sliding load during the tool operation, and the working environment and relative motion are complex, and the working conditions are harsh. ${ }^{18-20)}$ Therefore, evaluation methods that consider a single load or motion form are not suitable for the study of the tribological properties of cemented carbides under complex working conditions.

Impact-sliding wear is a typical and complex wear process that refers to the coupling of impact and sliding loads during relative motions. ${ }^{21)}$ In this study, a wear test set-up for cyclic impact-sliding was designed and employed to investigate the tribological behavior, damage evolution, and failure mechanism of cemented carbides under impact-sliding wear

*Corresponding author, E-mail: tdqtx2@163.com conditions. The results provide an understanding of the damage trend of cemented carbides under complex relative motions and loading conditions.

\section{Experimental}

\subsection{Materials}

In this experiment, we selected a ball and plane sample, i.e., a point-surface contact was investigated. The plane sample consisted of cemented carbide. The composition of the cemented carbide used in this study was $\mathrm{W}_{\mathrm{WC}+\text { additive }}=$ $90 \%, \mathrm{~W}_{\mathrm{Co}}=10 \%$. Its mechanical properties are listed in Table 1. The cemented carbide was processed into flat samples with a size of $20 \mathrm{~mm} \times 10 \mathrm{~mm} \times 8 \mathrm{~mm}$; the surface roughness $\mathrm{Sa}$ of the samples after polishing was $0.054 \mu \mathrm{m}$. The $\mathrm{Si}_{3} \mathrm{~N}_{4}$ ceramic sample was ground to obtain spheres with $\Phi=9.525 \mathrm{~mm}$. The chemical components and main mechanical properties of the $\mathrm{Si}_{3} \mathrm{~N}_{4}$ ceramic spheres are listed in Table 2.

\subsection{Impact-sliding test}

Figure 1(a) illustrates the schematic diagram of the impactsliding friction test device used in this experimental research. The device uses a servo motor as a power source to drive an eccentric disk. The eccentric disk is connected to the connecting rod of the transmission mechanism, the impact shaft, and the spring leaf. The impact shaft's middle part is guided by a linear slide rail, and the spring piece is connected to the clamp of the impact sample. The clamp of the plane sample is installed on a precision lifting table, and a dynamic piezoelectric sensor is installed between the plane sample holder and the precision lifting table. Compared with a traditional impact test machine that uses a vibration exciter or a spring to provide the impact load, a reciprocating impact device that uses a servo motor-driven linkage mechanism is used in this device to provide a wide range of the impact load, displacement, and frequency for simulating various impact-sliding wear conditions.

The test was conducted in an atmospheric environment at room temperature, and the relative humidity $(\mathrm{RH})$ of the 
Table 1 The main mechanical properties of the cemented carbide.

\begin{tabular}{ccccc}
\hline Material & TRS (MPa) & Microhardness $\left(\mathrm{kg} / \mathrm{mm}^{2}\right)$ & Elastic modulus $(\mathrm{GPa})$ & Density $\left(\mathrm{gcm}^{3}\right)$ \\
\hline K40UF & 3600 & $1350 \pm 50$ & 102 & 14.5 \\
\hline
\end{tabular}

Table 2 Main components and mechanical properties of the $\mathrm{Si}_{3} \mathrm{~N}_{4}$ ceramic material.

\begin{tabular}{|c|c|c|c|c|c|c|c|c|}
\hline \multicolumn{5}{|c|}{ Chemical composition (wt\%) } & \multicolumn{4}{|c|}{ Mechanical properties } \\
\hline $\begin{array}{c}\text { Materi } \\
\text { al }\end{array}$ & $\mathrm{Si}$ & $\mathrm{N}$ & $\mathrm{Fe}$ & $\mathrm{Al}$ & $\begin{array}{c}\text { Elastic } \\
\text { modulus } \\
(\mathrm{GPa})\end{array}$ & $\begin{array}{l}\text { TRS } \\
\text { (MPa } \\
\text { ) }\end{array}$ & $\begin{array}{l}\text { Tensile } \\
\text { strength } \\
\text { (MPa) }\end{array}$ & $\begin{array}{l}\text { Microhardnes } \\
\mathrm{s}\left(\mathrm{kg} / \mathrm{mm}^{2}\right)\end{array}$ \\
\hline $\mathrm{Si}_{3} \mathrm{~N}_{4}$ & $\begin{array}{c}62 . \\
0 .\end{array}$ & $\begin{array}{c}37 . \\
5\end{array}$ & $<0.2$ & $<0.2$ & 310 & 1200 & 2800 & $1500 \sim 1800$ \\
\hline
\end{tabular}
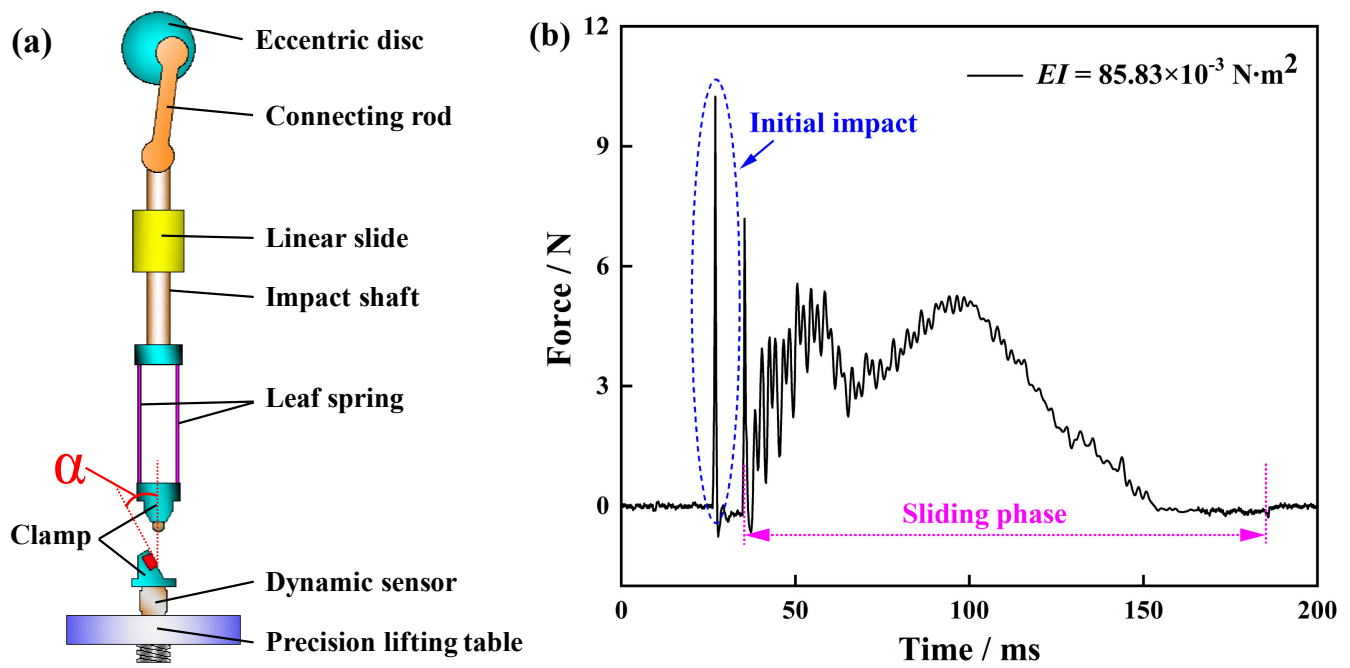

Fig. 1 (a) Schematic of the impact-sliding wear test device and (b) typical force curve of one cycle of the impact-sliding wear test.

air was $60 \pm 10 \%$. The test parameters were as follows: thickness of the spring leaf $=1 \mathrm{~mm}$, bending stiffness $E I=$ $85.83 \times 10^{-3} \mathrm{~N} \cdot \mathrm{m}^{2}$, sliding amplitude $\mathrm{S}=2 \mathrm{~mm}$, impact angle $\alpha=30^{\circ}$, impact slip frequency $\mathrm{f}=1 \mathrm{~Hz}$. We analyzed the damage behavior and characteristics of the cemented carbide at different cycles of the test $(N=100,500,1000$, and 2000) to determine the damage evolution of the cemented carbide during impact-sliding wear conditions. In this test, the contact force was not the input parameter but represented a test output because it was affected by the impact energy, structural stiffness, and friction interface morphology. ${ }^{21,22)}$ Figure 1(b) shows a typical force curve of one cycle of the impact-sliding wear test.

\subsection{Measurements and observations}

After the impact-sliding wear test, the samples were cleaned and dried, and an optical microscope (OM, OLYMPUS-BX60M, Japan) and scanning electron microscope (SEM, JSM-6610LV, Japan) were used to observe the macro and micromorphology of the wear scar surface. We used a three-dimensional optical profiler (3D-OM, BRUKER NPFLEX, USA) to measure the 3D profile of the samples. We used a X-ray photoelectron spectrometer
(XPS, ESCALAB 250Xi) to perform microscopic chemical component analysis of typical damage areas of the wear scars to assess the damage behavior and mechanism of the materials under impact-sliding wear conditions.

\section{Results and Discussion}

\subsection{Impact-sliding damage responses \\ 3.1.1 Macromorphology characteristics}

Figure 2 shows the OM images of the wear scars of the cemented carbide surface after applying different numbers of impact and sliding cycles. The wear scars can be divided into two areas: the impact zone and the sliding zone. The damage characteristics of the two zones are considerably different. As shown in Fig. 2(a), after 100 test cycles, uneven damage occurred in the impact area, and the generation of black wear debris was observed; only slight scratches were observed in the sliding zone, and no significant damage was observed. As the number of cycles increased to 500 (Fig. 2(b)), it was observed that the wear debris was discharged outside the wear scar. The entire inside of the wear scar and the sliding zone were polished, and the width of the wear scar increased. With the increase of the number of cycles, the black wear 

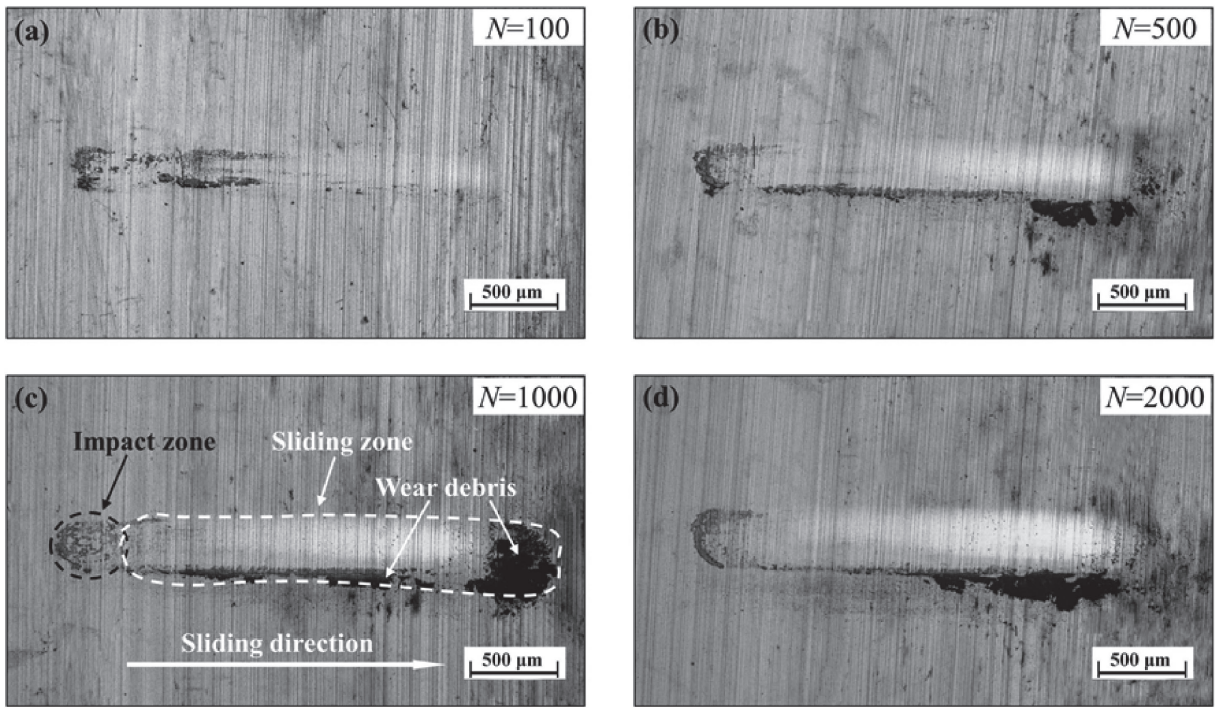

Fig. 2 Comparative analysis of the OM images of the wear scars of the cemented carbide surface for different cycles.
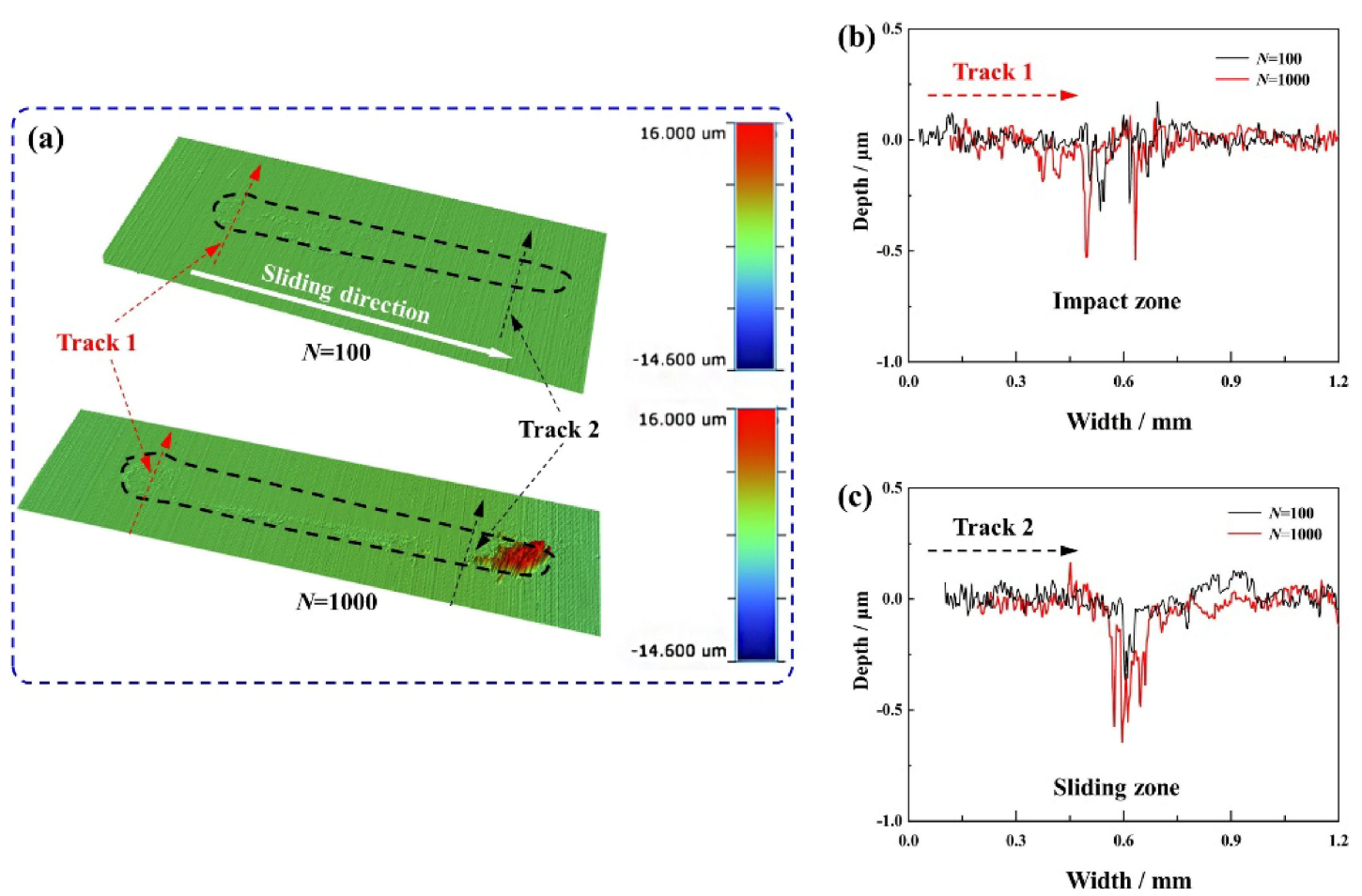

Fig. 3 Contrast analysis of the wear scar for different numbers of impact-sliding cycles: (a) three-dimensional results, (b) two-dimensional results of the impact zone, (c) two-dimensional results of the sliding zone.

debris outside the wear scar continued to accumulate, while the wear widths were not significantly increased ((c) and (d)).

\subsubsection{D and 3D profiles}

Figure 3 shows the wear profile analysis of the cemented carbide surface under impact-sliding wear after 100 and 1000 cycles. As shown in Fig. 3(a), wear scars were observed in the initial position only after 100 impact-sliding cycles. In other words, the impact area, a few slight wear marks, and the damage occurred in a few small spots. Micro-damage was observed in the sliding zone of the wear scars. The reason was the low number of test cycles and the relatively small wear accumulation. The 3D results of the wear scars after 1000 cycles shows that the overall wear was still relatively slight, but the impact area of the wear scars was rougher than after 100 cycles. Compared with the unworn area, the surface of the sliding zone of the wear scars was smoother, and the tail of the wear scar had accumulated wear debris with a height of about $7.5 \mu \mathrm{m}$. As the number of cycles increased from 100 to 1000 , the wear scars in the impact zone became more pronounced; however, the sliding zone wear showed no significant increase except for the polished surface.

Figure 3(b) and 3(c) show the two-dimensional results of the wear scars in the impact zone and the sliding zone in the vertical direction in track 1 and track 2 . In the impact zone, the damage degree of the wear scar was much lower after 100 cycles than after 1000 cycles. The maximum wear depths in 


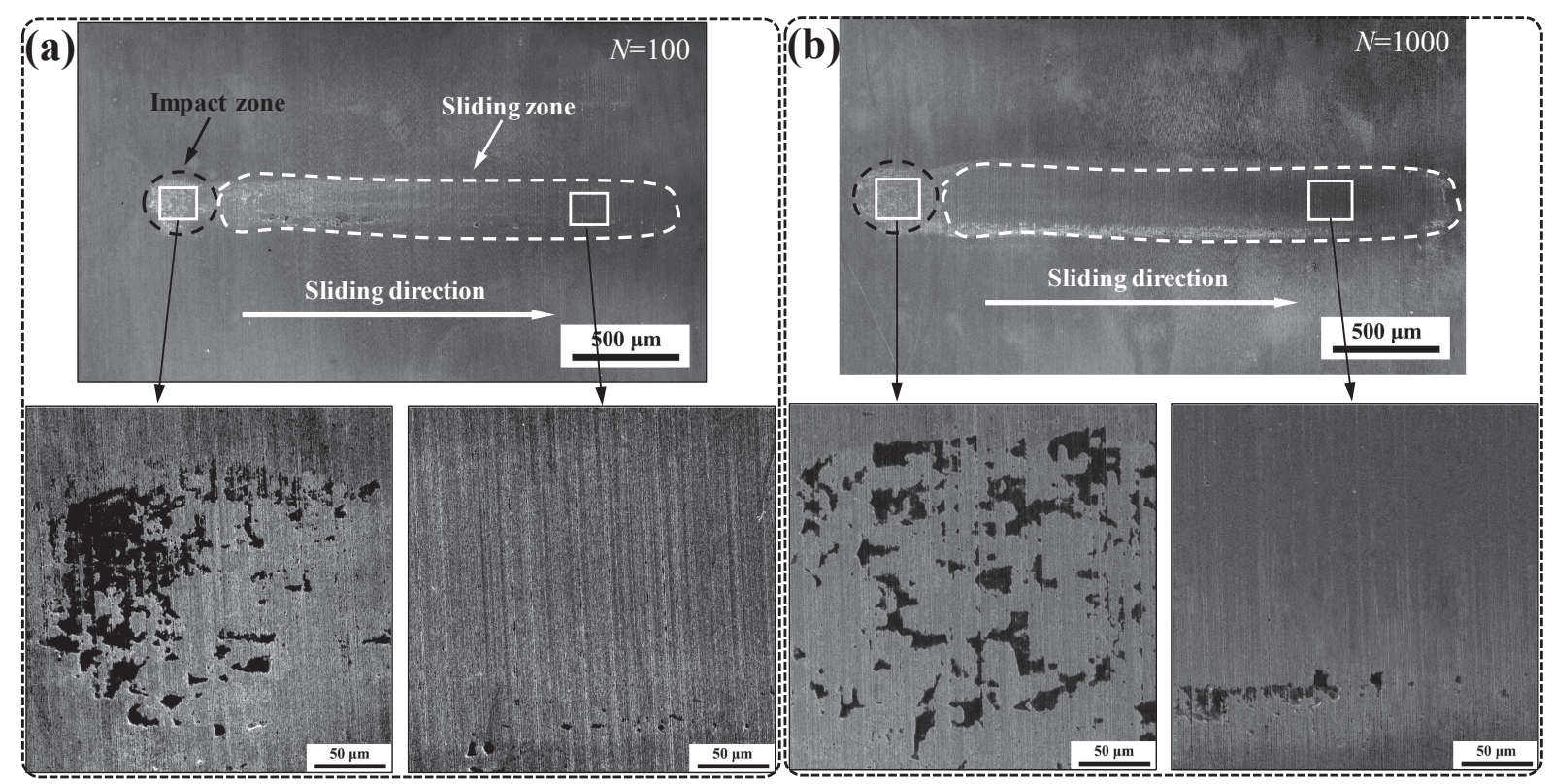

Fig. 4 SEM images of the wear scars of the cemented carbide surface: (a) $N=100$, (b) $N=1000$.

this zone were $0.32 \mu \mathrm{m}$ and $0.63 \mu \mathrm{m}$, respectively. Both wear scars had deep pits, and the curve shows that the surface of the impact area was very rough. The damage characteristics of the wear scars were similar for the different number of cycles. The curves were smoother in the sliding zone than the impact zone, and the maximum wear depths were $0.35 \mu \mathrm{m}$ and $0.64 \mu \mathrm{m}$, respectively, representing a two-fold increase. This finding indicated that the degree of damage was not linearly related to the number of cycles, and the wear rate decreased as the number of cycles increased. The main damage zone and characteristics of the impact-sliding wear of the cemented carbide surface did not change significantly.

\subsubsection{Micromorphology characteristics}

Figure 4(a) shows the SEM image of the micromorphology of the wear scars of the cemented carbide surface after 100 impact-sliding wear cycles. Similar to the OM images, these results show that the characteristics of the impact zone and sliding zone of the wear scars were significantly different. The cemented carbide was only slightly damaged, and large areas of flaking damage were observed in the impact area. Black wear products were generated, and spalling damage was unevenly distributed in the impact area; the damage in the sliding zone of the wear scars was slight, and the surface condition was similar to that of the unworn surface.

Figure 4(b) shows the wear scar damage of the cemented carbide for 1000 test cycles. The impact zone also showed flaking and peeling damage, and black wear products were observed. However, the spalling range was smaller than in the test with 100 cycles. In the sliding area, the roughness of the wear scar was lower than that of the unworn area, and no damage characteristics were observed. Therefore, the wear damage of the cemented carbide under impact-sliding was primarily peeling damage in the impact area, whereas the sliding area mostly experienced deformation and polishing in the sliding zone.

The SEM analysis showed that in the early stage of the impact-sliding wear test (100 test cycles), peeling damage occurred in the impact area of the wear scar. However, as the number of test cycles increased, the peeled wear debris in the impact area was continuously crushed, although the overall damage of the wear scar increased. The peeling damage was minimal, whereas the sliding zone was polished, and the damage increased slowly. Hence, the impact-sliding wear of the cemented carbide accumulated quickly due to the peeling damage in the initial stage. As the number of cycles increased, the degree of peeling damage, and the wear accumulation decreased.

\subsection{Impact-sliding wear behavior of the cemented carbide}

\subsubsection{Chemical analysis of the unworn surfaces}

We conducted a chemical analysis of the unworn surface of the cemented carbide. Figure 5 shows the XPS narrowspectrum results of the three main elements $\mathrm{C}, \mathrm{W}$, and Co on the initial surface of the sample. In this study, the carbon, which was the result of external adventitious carbon contamination was used as the standard peak position of the XPS spectrum. The peak position of $\mathrm{C}-\mathrm{C}$ was set to $284.6 \mathrm{eV}$ by default. The result of $\mathrm{C} 1 \mathrm{~s}$ in Fig. 5(a) shows that the main chemical states of $\mathrm{C}$ were $\mathrm{C}-\mathrm{C}, \mathrm{WC}, \mathrm{C}-\mathrm{O}-\mathrm{C}$, and $\mathrm{O}-\mathrm{C}=\mathrm{O}$, and the main peaks were carbon from adventitious carbon contamination. Hence, the chemical state of $\mathrm{C}$ in the cemented carbide was mainly WC. The Co in the cemented carbide sample oxidizes rapidly in the air. The $\mathrm{W} 4 \mathrm{f}$ results in Fig. 5(b) indicate that $\mathrm{W}$ was mainly in the form of a simple substance. The peak positions correspond-

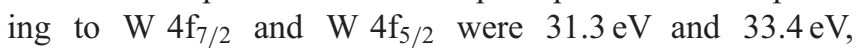
respectively. Additionally, a small amount of $\mathrm{W}$ existed as

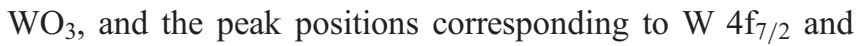
$\mathrm{W} 4 \mathrm{f}_{5 / 2}$ were $35.0 \mathrm{eV}$ and $37.1 \mathrm{eV}$, respectively. The results of the XPS analysis show the state of Co on the sample surface. The Co $2 p$ results in Fig. 5(c) show that this element was in the $\mathrm{CoO}$ state. The Co $2 \mathrm{p}_{3 / 2}$ peak was at $779.8 \mathrm{eV}$, and the accompanying peak was at $785.0 \mathrm{eV}$; the Co $2 \mathrm{p}_{1 / 2}$ 

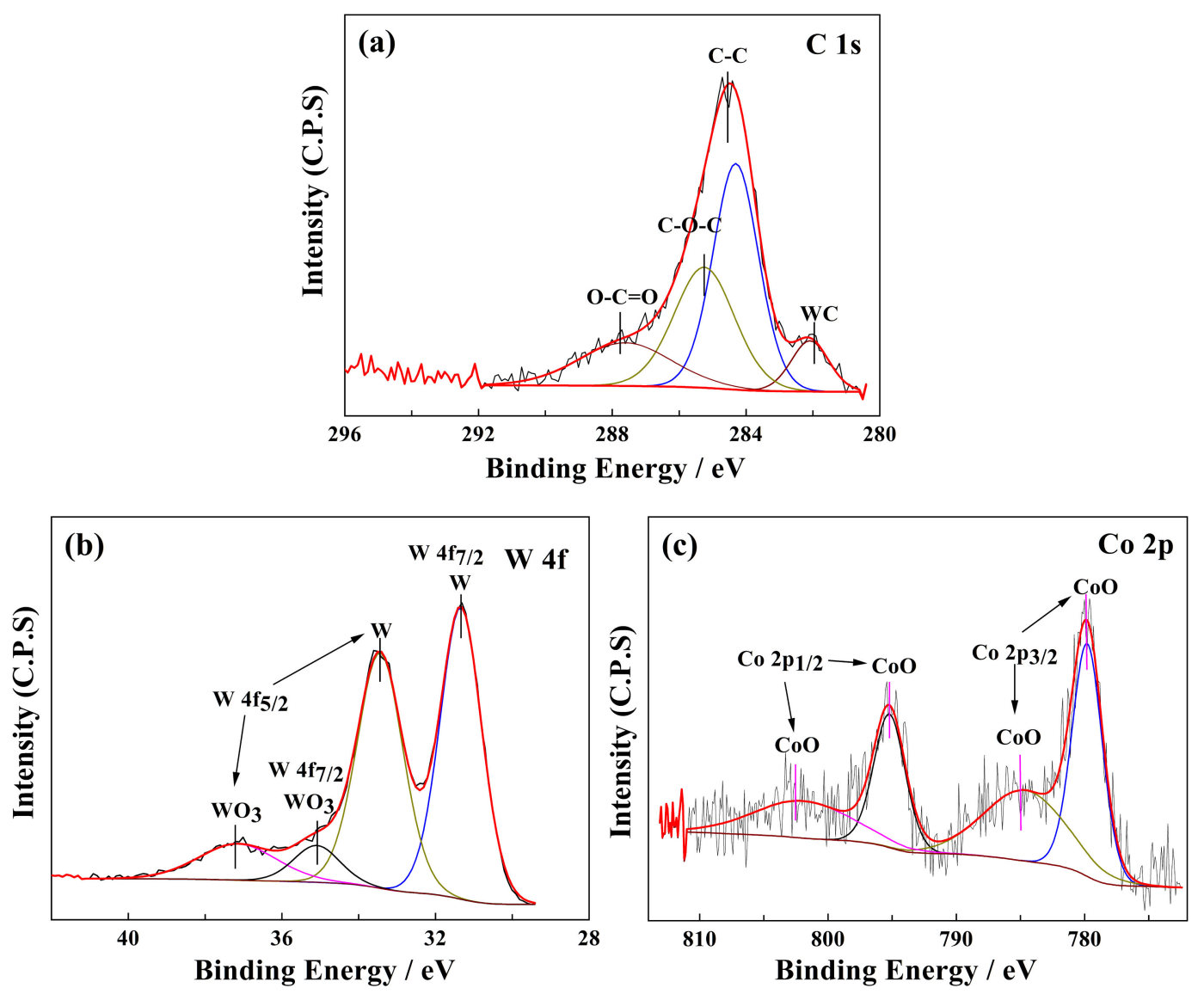

Fig. 5 XPS narrow-spectrum results of the cemented carbide unworn surface; (a) C, (b) W, (c) Co.

peak was at $795.3 \mathrm{eV}$, and the accompanying peak was at $802.6 \mathrm{eV}$. Therefore, the $\mathrm{W}$ on the cemented carbide surface was partially oxidized, whereas all of the Co in the surface layer was oxidized, and $\mathrm{CoO}$ was formed.

\subsubsection{Composition analysis of the wear scars}

To further analyze the chemical state of the wear scar surface, XPS analysis was performed on the impact zone and sliding zone of the wear scars after 1000 cycles of the impactsliding wear tests. The results are shown in Figs. 6 and 7. It is observed from Fig. 6(a) that, compared with the original surface of the cemented carbide, the $\mathrm{C}$ in the impact zone was further oxidized, and the $\mathrm{O}-\mathrm{C}=\mathrm{O}$ bond appeared. After impact-sliding wear, the most significant change in the chemical state of the elements in the impact area of the wear scars was observed in the W. The chemical state of $\mathrm{W}$ on the original surface of the cemented carbide was a simple substance, and a very small amount of $\mathrm{WO}_{3}$ was present. In contrast, the proportion of $\mathrm{WO}_{3}$ in the impact zone substantially increased after impact-sliding wear, and the proportions of $\mathrm{W}$ and $\mathrm{WO}_{3}$ were similar (Fig. 6(b)). Additionally, the chemical bond energy of $\mathrm{WO}_{3}$ in the wear scar in the impact zone was higher than that of the unworn cemented carbide, and the peak position had shifted to the left by $0.7 \mathrm{eV}$, resulting in peaks at $35.7 \mathrm{eV}$ and $37.8 \mathrm{eV}$ for $\mathrm{W} 4 \mathrm{f}_{7 / 2}$ and $\mathrm{W} 4 \mathrm{f}_{5 / 2}$, respectively. This finding indicated that the degree of oxidation of $\mathrm{W}$ in the impact zone had substantially increased. The peak position of the $\mathrm{W}$ had not changed, and the peaks corresponding to $\mathrm{W} 4 \mathrm{f}_{7 / 2}$ and
$\mathrm{W} 4 \mathrm{f}_{5 / 2}$ were still located at $31.3 \mathrm{eV}$ and $33.4 \mathrm{eV}$. Figure 6(c) shows that the $\mathrm{Co}$ in the wear scars in the impact zone was in the $\mathrm{CoO}$ state, and the peak of $\mathrm{Co} 2 \mathrm{p}_{3 / 2}$ was at $779.8 \mathrm{eV}$, and the accompanying peak was at $785.0 \mathrm{eV}$. The Co $2 \mathrm{p}_{1 / 2}$ peak was at $795.3 \mathrm{eV}$, and its accompanying peak was at $802.6 \mathrm{eV}$. These results were consistent with those of the unworn surface of the cemented carbide. The black wear products in the impact zone of the cemented carbides after the impact-sliding test were mainly $\mathrm{WO}_{3}$. In the impactsliding wear process, the tungsten element inside the material is exposed on the friction interface and forms a protective oxide $\mathrm{WO}_{3}$ with the wear of the surface material, and friction heat will accelerate this process. The impactsliding wear increased the oxidation degree of the elements in the impact zone. In particular, the degree of oxidation of $\mathrm{W}$ significantly increased, and oxidative wear occurred in the impact zone.

The XPS results of the wear scars in the sliding zone in Fig. 7 demonstrate that the degree of oxidation of the $\mathrm{C}$ was slightly higher than that of the unworn surface, and the states of $\mathrm{W}$ and Co were consistent with those of the unworn surface. The $\mathrm{W}$ mainly existed in the form of a simple substance, and the peak position had not changed; there was also a small amount of $\mathrm{WO}_{3}$. The Co $2 \mathrm{p}$ results revealed that the $\mathrm{Co}$ was in the $\mathrm{CoO}$ state, and the accompanying peak of $\mathrm{CoO}$ had almost vanished. Therefore, the degree of oxidative wear of the cemented carbide in the sliding area was lower than that in the impact area. 

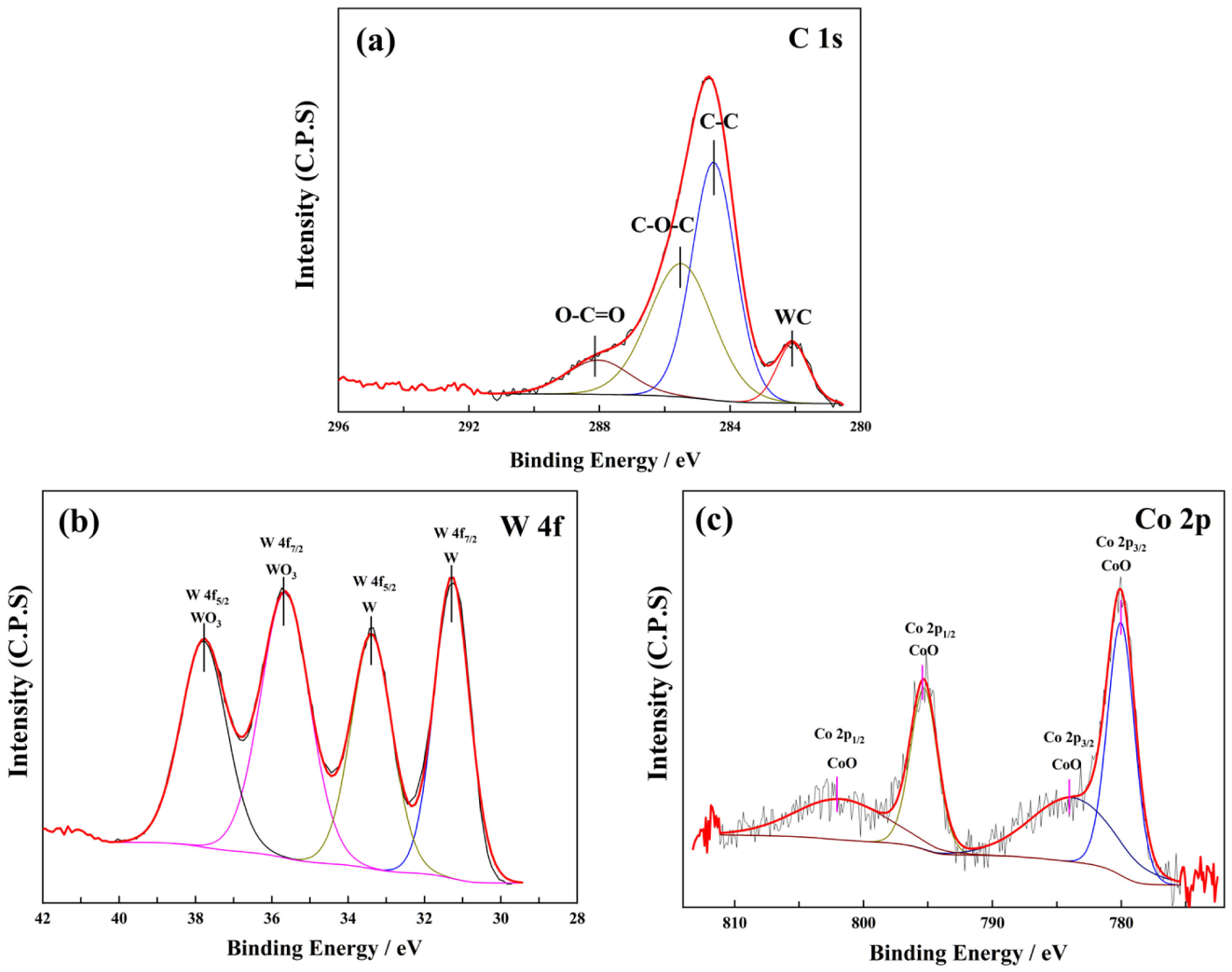

Fig. 6 XPS results of the wear scars in the impact zone; (a) C, (b) W, (c) Co.
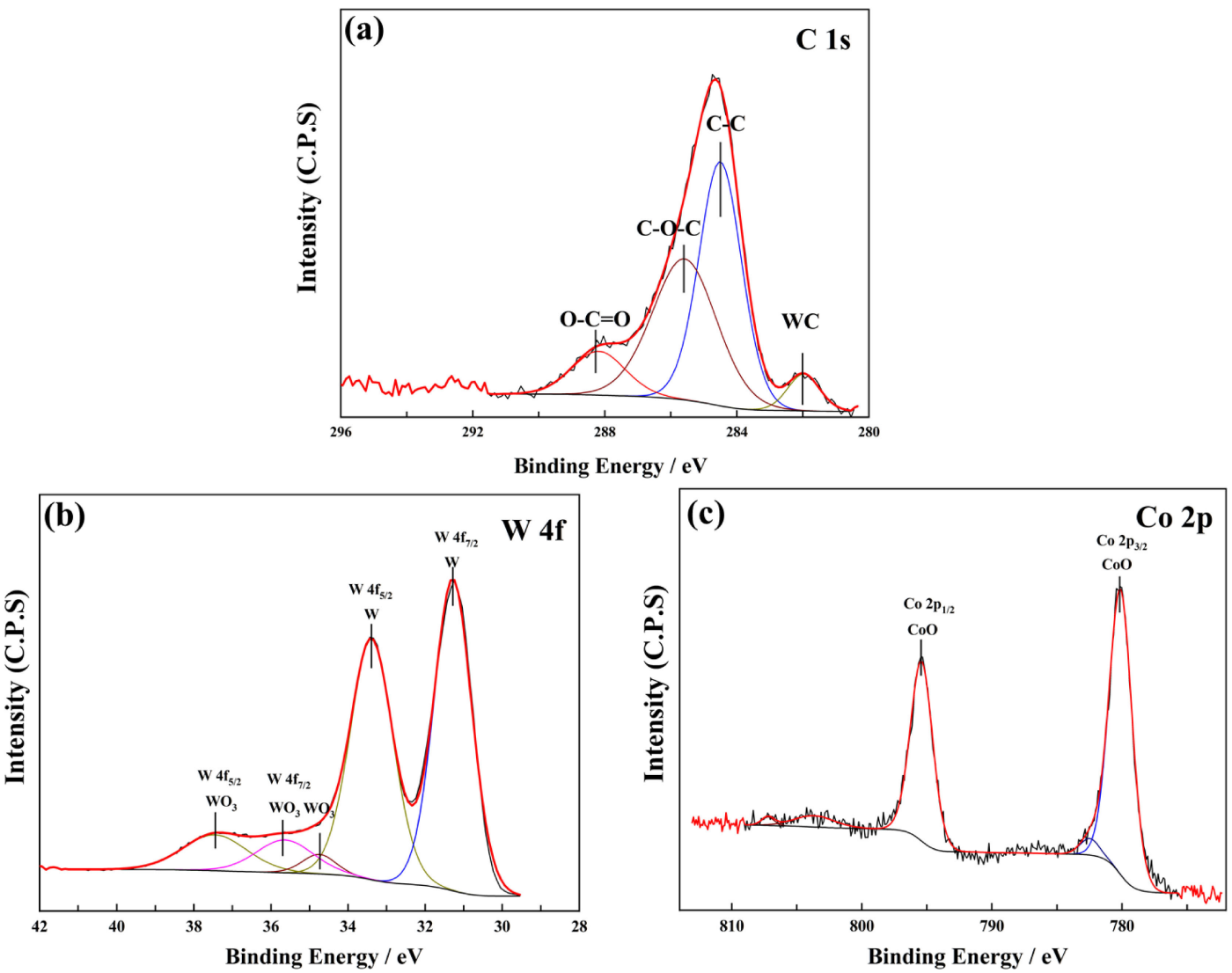

Fig. 7 XPS results of the wear scars in the sliding zone; (a) C, (b) W, and (c) Co. 


\section{Conclusions}

In view of the complex wear engineering background of tunnel boring tools, this study investigated the impactsliding wear characteristics of cemented carbide materials. The main purpose is to provide an understanding of the damage trend of cemented carbides under complex relative motions and loading conditions. The main conclusions are as follows:

(1) The primary damage of cemented carbide under impactsliding wear was peeling damage in the impact zone, whereas the damage in the sliding zone was mainly deformation coordination. In addition, polishing was observed in the sliding zone.

(2) In the early stage of impact-sliding wear, the impact area of the cemented carbide wear scar exhibited peeling damage, and impact-sliding wear accumulated rapidly. As the number of test cycles increased, the main damage areas and characteristics of impact-sliding wear showed no substantial change, but the wear rate decreased.

(3) After impact-sliding wear, the cemented carbide wear scar showed accumulations of black $\mathrm{WO}_{3}$ in the impact zone. As the number of cycles of the impact-sliding test increased, the degree of oxidation of $\mathrm{W}$ in the impact zone of the wear scar increased, and the chemical bond energy of $\mathrm{WO}_{3}$ increases.

(4) The impact-sliding wear mechanisms of the cemented carbide included fatigue wear and oxidative wear, and the dominant damage form was delamination.

\section{Acknowledgments}

This research was funded by Sichuan Science and Technology Program (Grant No. 2020YJ0192 and 2019YJ0395).

\section{REFERENCES}

1) J. Garcia, V.C. Cipres, A. Blomqvist and B. Kaplan: Int. J. Refract. Met. Hard Mater. 80 (2019) 40-68.

2) J. Sun, J. Zhao, F. Gong, X.Y. Ni and Z.L. Li: Crit. Rev. Solid State Mater. Sci. 44 (2019) 211-238.

3) A. Shemi, A. Magumise, S. Ndlovu and N. Sacks: Miner. Eng. 122 (2018) 195-205.

4) S. Saketi, S. Odelros, J. Ostby and M. Olsson: Materials 12 (2019) 2822.

5) K. Hoshino, Y. Yamasaki, W. Tanimoto, M. Nagoshi, S. Taira and N. Yoshimi: Mater. Trans. 58 (2017) 873-879.

6) M. Shioda, T. Mochizuki and Y. Kishimoto: Mater. Trans. 62 (2021) 526.

7) B.C.M. Reis, A. dos Santos, N.F.P. dos Santos, M.A. Camara, P.E. de Faria and A.M. Abrao: Int. J. Adv. Manuf. Technol. 105 (2019) 1655-1663.

8) P. Gao, X.B. Wang, Z.Q. Liang, J.F. Xiang, W. Li and J.Q. Xie: Int. J. Adv. Manuf. Technol. 104 (2019) 2401-2413.

9) J. Heinrichs, S. Norgren, S. Jacobson, K. Yvell and M. Olsson: Int. J. Refract. Met. Hard Mater. 85 (2019) 105035.

10) F.G. Zhang: Ceram. Int. 45 (2019) 15327-15333.

11) Q.B. Yue, H.B. He, H.Y. Li, J. Zhang, Y.M. Li and L. Ma: Int. J. Precis. Eng. Manuf. 20 (2019) 1581-1589.

12) G.L. Zhang, Y.C. Wang, Y. Liu, X.F. Liu and Y.M. Wang: Friction 7 (2019) 217-226.

13) B.D. Li and Z.Y. Rui: Adv. Mech. Eng. 11 (2019) 1.

14) P. Olander and J. Heinrichs: Wear 426 (2019) 1658-1666.

15) B.D. Beake, L. Isern, J.L. Endrino and G.S. Fox-Rabinovich: Wear 418 (2019) 102-110

16) S. Al Wohaibi, A.S. Mohammed, T. Laoui, A.S. Hakeem, A.Y. Adesina and F. Patel: Materials 12 (2019) 920.

17) W. Song, Z. Xia, S. Wang and X. Zhang: Materials 11 (2018) 1248.

18) M. Fall, G. Bouvard, G. Guillonneau, V. Fridrici and P. Kapsa: Wear 376 (2019) 372-383.

19) C. Wang, C.W. Zhang, L. Gu, M.L. Bi, P.P. Hou, D.Z. Zheng and L.Q Wang: Tribol. Int. 150 (2020) 106384.

20) K. Guo, C. Tian, Y.P. Wang, Y. Wang and W. Tan: Tribol. Int. 148 (2020) 106305.

21) D.Q. Tan, J.L. Mo, J.F. He, J. Luo, Q. Zhang, M.H. Zhu and Z.R. Zhou: Proc. Inst. Mech. Eng. Part J 233 (2019) 1844-1856.

22) D.Q. Tan, J.L. Mo, W.F. He, J. Luo, Q. Zhang, M.H. Zhu and Z.R. Zhou: Surf. Coat. Technol. 358 (2019) 22-35. 